Brief Report

\title{
Astrovirus in Reunion Free-Tailed Bat (Mormopterus francoismoutoui)
}

\author{
Léa Joffrin ${ }^{+} \mathbb{D}$, Axel O. G. Hoarau, Erwan Lagadec, Marie Köster, Riana V. Ramanantsalama, Patrick Mavingui \\ and Camille Lebarbenchon *
}

INSERM 1187, CNRS 9192, IRD 249, 2 rue Maxime Rivière, UMR Processus Infectieux en Milieu Insulaire Tropical (PIMIT), Université de La Réunion, 97490 Saint Denis de La Réunion, France; lea.joffrin@gmail.com (L.J.); axel.hoarau@univ-reunion.fr (A.O.G.H.); erwan.lagadec69@yahoo.fr (E.L.); marie.koster@univ-reunion.fr (M.K.); riana.ramananstalama@univ-reunion.fr (R.V.R.); patrick.mavingui@univ-reunion.fr (P.M.)

* Correspondence: camille.lebarbenchon@univ-reunion.fr

+ Present address: Evolutionary Ecology Group, Department of Biology, University of Antwerp, Universiteitsplein 1, 2610 Antwerp, Belgium.

Citation: Joffrin, L.; Hoarau, A.O.G.; Lagadec, E.; Köster, M.;

Ramanantsalama, R.V.; Mavingui, P.; Lebarbenchon, C. Astrovirus in Reunion Free-Tailed Bat (Mormopterus francoismoutoui). Viruses 2021, 13, 1524 https://doi.org/10.3390/v13081524

Academic Editors: Kateri Bertran, Martí Cortey and Miria F. Criado

Received: 4 June 2021

Accepted: 27 July 2021

Published: 2 August 2021

Publisher's Note: MDPI stays neutral with regard to jurisdictional claims in published maps and institutional affiliations.

Copyright: (c) 2021 by the authors. Licensee MDPI, Basel, Switzerland. This article is an open access article distributed under the terms and conditions of the Creative Commons Attribution (CC BY) license (https:/ / creativecommons.org/licenses/by/ $4.0 /)$.
Abstract: Astroviruses (AstVs) are RNA viruses infecting a large diversity of avian and mammalian species, including bats, livestock, and humans. We investigated AstV infection in a free-tailed bat species, Mormopterus francoismoutoui, endemic to Reunion Island. A total of 380 guano samples were collected in a maternity colony during 38 different sampling sessions, from 21 June 2016 to 4 September 2018. Each sample was tested for the presence of the AstV RNA-dependent RNApolymerase (RdRp) gene using a pan-AstV semi-nested polymerase chain reaction assay. In total, 27 guano samples $(7.1 \%)$ tested positive, with high genetic diversity of the partial RdRp gene sequences among positive samples. Phylogenetic analysis further revealed that the detected viruses were genetically related to AstVs reported in rats, reptiles, dogs, and pigs, but did not cluster with AstVs commonly found in bats. Although more investigations need to be conducted to assess the prevalence of infected bats in the studied population, our findings show that Reunion free-tailed bats are exposed to AstVs, and suggest that cross-species transmission may occur with other hosts sharing the same habitat.

Keywords: Astroviridae; Molossidae; Reunion Island; Indian Ocean

\section{Introduction}

Astroviruses (AstVs; Family Astroviridae) are positive-sense single-stranded RNA viruses and have been detected in a large diversity of mammalian and avian species [1]. In humans, eight serotypes have been described worldwide, accounting for $2-9 \%$ of acute non-bacterial gastro-enteritis cases in children [2]. AstVs are also responsible for diseases in livestock, poultry, and domestic pets [1]. In wild animals, they have been mostly described in bats ([3] and in aquatic birds [4], although detection in other hosts has been reported, such as in marine mammals [5] and in non-human primates [6]. In addition to this large host diversity, the evolutionary history of AstVs is characterized by frequent cross-species transmission events [7], supporting limited host specificity and a risk of spillover and emergence in humans [8].

AstVs have been reported in African insectivorous bats, in particular in species of the Miniopteridae and Rhinonycteridae families [9-12]. Detection rates vary greatly depending on the study design and the tested species [3], and the prevalence of bat shedding AstVs within populations is also highly variable. For instance, we estimated the prevalence of shedding bats ranging from $20 \%$ to $81 \%$ for Triaenops afer in Mozambique, depending on the time of sample collection [9]. Such a strong seasonality has been reported in both tropical and temperate regions and could be associated to bat population dynamics, in particular in maternity colonies (e.g., an increase in the population size and density during 
the formation of the colony; [13]). Body condition and co-infection with other viruses have also been identified to be positively correlated with AstV infection in bats $[14,15]$.

The islands of the Western Indian Ocean host eleven of the twenty bat families described worldwide [16], with a highly contrasted diversity pattern between islands. Madagascar shelters 46 bat species, of which nearly $80 \%$ are endemic $[17,18]$. In contrast, the small oceanic islands surrounding Madagascar are inhabited by a limited number of bat species. For instance, only three species occur on Reunion Island, and only one of them, the Reunion free-tailed bat (RFTB; Mormopterus francoismoutoui; Molossidae), is endemic to the island.

RFTB is the most abundant bat species on Reunion Island. This small insectivorous species roosts in large colonies in natural caves and synanthropic habitats such as bridges and houses [19]. Based on guano sampling in an RFTB maternity colony, we investigated the temporal variation in AstV shedding for more than 2 years (28 consecutive months), with a particular emphasis on the parturition period. Partial sequencing of the AstV RNAdependent RNA-polymerase (RdRp) gene and phylogenetic analyses were performed to assess the diversity and the origin of the detected viruses.

\section{Material and Methods}

The study was conducted in the main RFTB colony known to date on Reunion island, within a natural cave of $30 \mathrm{~m}^{3}$ on the West coast of the island $\left(21,111^{\circ} \mathrm{S}, 55,259^{\circ} \mathrm{E}\right)$. The colony is monospecific and mostly composed of adult females during the early stages of the breeding season (October to December); and of neonates and juveniles, after the parturition period (from mid-December onward; Dietrich et al., 2015). Between 40,000 and 50,000 flying adult bats have been estimated before parturition; however, after the breeding season, the cave remains totally empty from bats (May to September) [20].

A non-invasive sampling was set up to limit colony disturbance. During each sampling session, we collected guano samples in the narrowest part of the cave entrance, in ten different sampling points separated by $50 \mathrm{~cm}$ along a $4.5 \mathrm{~m}$ transect (Supplementary Figures S1 and S2). Sterile open-ended $2 \mathrm{~mL}$ syringes were used to collect a core sample, in order to obtain c. $130 \mathrm{mg}$ of guano. Each guano sample was immediately mixed with $1.5 \mathrm{~mL}$ of Virus Transport Media (VTM; e.g., [21]). Samples were maintained in a cooler with ice packs in the field and stored in a $-80{ }^{\circ} \mathrm{C}$ freezer within two hours.

In total, 380 samples were collected during 38 different sampling sessions between 21 June 2016 and 4 September 2018. During each sampling session, the colony was visually monitored in order to classify the relative population size (no bat, less than half of the cave covered with bats, and more than half of the cave covered), and to assess the population age, structure, and timing of parturition based on the presence of adults, neonates, and juveniles.

Guano samples were mixed and centrifuged at $1500 \times g$ for $15 \mathrm{~min}$. RNA extraction was performed on $140 \mu \mathrm{L}$ of supernatant, with the QIAamp Viral RNA Mini Kit (QIAGEN, Valencia, CA, USA). Reverse-transcription was done on $10 \mu \mathrm{L}$ of RNA using the ProtoScript II Reverse Transcriptase and Random Primer 6 (New England BioLabs, Ipswich, MA, USA) [21]. cDNAs were tested for the presence of the AstV RdRp gene using a pan-AstV semi-nested polymerase chain reaction (PCR) assay [22]. PCR products of the expected size were submitted for direct Sanger sequencing (Genoscreen, Lille, France). Chi-square tests were conducted to investigate the effects of the sampling date and the sampling location in the transect, on the probability of successful detection of the AstV RdRp gene. Statistical analyses were conducted with R 3.4.4 [23].

A phylogenetic analysis was performed on the RdRp gene sequences obtained in this study (GenBank accession numbers MK966904 to MK966918, and MZ274075 to MZ274086) and 84 reference RdRp sequences of AstVs detected in a large diversity of bat species, in particular from Africa (Madagascar, Mozambique, and Gabon), as well as in other vertebrate hosts (e.g., avian, human, and livestock). Sequences were aligned with the CLC Sequence Viewer 8.0 (CLC Bio, Aarhus, Denmark). Maximum-likelihood analysis was 
conducted using PhyML 3.1 [24], with an evolutionary model selected by Model Generator $0.85(\mathrm{GTR}+\mathrm{I}+\Gamma \mathrm{I}=0.13, \alpha=0.83 ;[25]$, and 1000 bootstraps.

\section{Results and Discussion}

In total, 27 guano samples (7.1\%) tested positive for the presence of $\mathrm{AstV}$, without differences between the sampling location along the transect $\left(\chi^{2}=11.8 ; \mathrm{df}=9 ; p=0.23\right)$. Although no variation was observed between the two sampling seasons $\left(\chi^{2}=0.17 ; \mathrm{df}=1\right.$; $p=0.68)$, significant differences in the number of positive samples between sampling dates were detected $\left(\chi^{2}=74.8 ; \mathrm{df}=37 ; p<0.001\right)$, with AstVs mostly detected after the parturition period (late December), in February and March (Figure 1). This pattern suggests a potential effect of the population age structure [14] rather than changes in size and density associated with the formation of the colony [13]. A previous investigation on paramyxovirus and Leptospira spp. infection dynamics in the same bat colony revealed two peaks of infection: one during the colony formation and the other two months after the birth pulse [20]. The latter may coincide with the detection of most AstVs in February and March, and the first one with the positive samples detected in December. Although these results support the occurrence of AstV RNA in the RFTB environment, our sampling design precludes further conclusions on the prevalence of shedding bats in the population. Bat individual sampling is needed to further support AstV infection in RFTB and identify population-related factors involved in the temporal and spatial transmission dynamics.
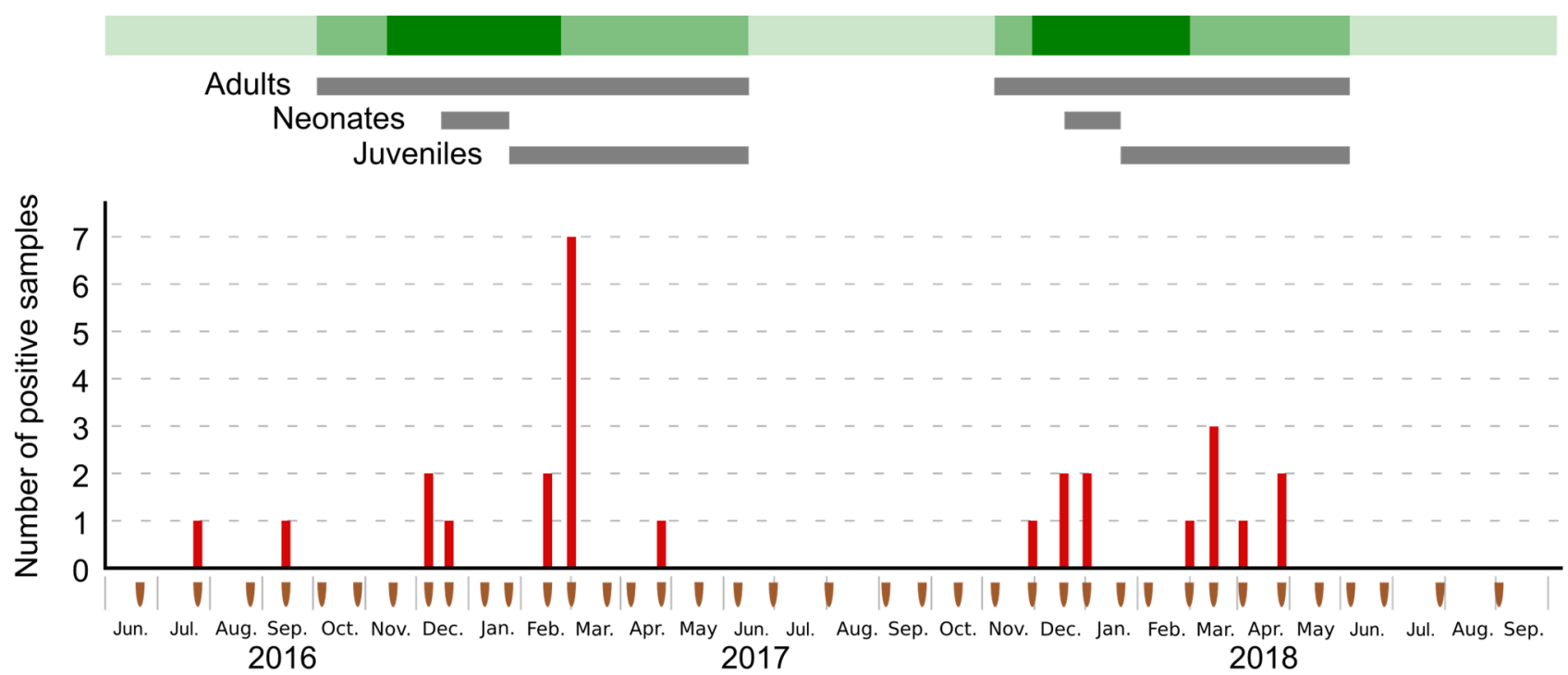

Figure 1. Number of Astrovirus positive guano samples as per sampling session (brown marks). Ten samples were collected during each sampling session. Green shading indicates the relative bat population size: light green: no bat inside the cave, mid-green: less than half of the cave occupied by bats, dark green: more than half of the cave occupied by bats. Presence of adults, neonates, and juveniles bats is represented by gray bars.

Two samples collected before the breeding season (in July and September 2016), when the cave was not occupied by bats, also tested positive for $\mathrm{Ast} V$, and suggest a possible environmental persistence of $\mathrm{Ast} \mathrm{V}$ RNA in bat guano. Ast $\mathrm{V}$ persistence in the environment could potentially favor bat infection during cave colonization at the beginning of the breeding season, but also create an opportunity for virus spillover to other vertebrate hosts. Rats (Rattus rattus) have been sighted in the vicinity and within the cave during the study period, and previous studies have shown that paramyxoviruses may be transmitted between rats and RFTB in the studied cave [20]. Bat guano is also used as a fertilizer for agricultural crops, worldwide, and is regularly harvested on a small scale by local farmers for personal use [26]. At our study site, bat guano was indeed harvested in the cave entrance throughout the course of the breeding season. The detection of viral RNA 
does not provide evidence of the maintenance of infectious particles in bat guano and virus isolation would be required to experimentally assess the infectious ability of bat AstVs outside their hosts. However, transmission routes of bat viruses to humans remain unclear [27], and given the high propensity of AstVs for cross-species transmission [7], our finding underlines that the risk of AstV spillover from bats to human should be fully investigated.

Analysis of the 27 RdRp partial sequences revealed a high genetic diversity (up to $49 \%$ of partial RdRp sequence differences). This finding is consistent with previous studies on bat AstVs in Madagascar [21], continental Africa [9-12], and other bat populations, worldwide. Such a high level of sequence diversity in a single bat species nevertheless contrasts with the low diversity measured for paramyxovirus and Leptospira in the same colony [20]). Classification of AstV based on host species origin has been largely challenged for the past years [28] because AstVs isolated from different animal species can be genetically similar $[9,11,21]$, but also because genetically different viruses can be isolated from a single species [11,29]. To improve AstVs classification, the International Committee on Taxonomy of Virus now recommends comparing the AstV RdRp gene to capsid gene sequences [2], although sequencing of the capsid remains challenging for bat-origin AstVs.

The phylogenetic analysis further revealed that the detected viruses were genetically related to AstVs found in rats, reptiles, dogs, cats, and pigs, but did not cluster in a single bat AstVs clade (Figure 2). This result could reflect the limited number of AstV nucleotide sequences available from Molossid bats in public databases, and, more broadly, from bats in tropical areas. Because our study was based on environmental sampling, however, we cannot exclude that the detected viruses came from other hosts than RFTB. As previously mentioned, rats, but also feral dogs (Canis lupus familiaris), and zebu (Bos taurus indicus), have been regularly sighted close to the cave entrance. Avian species such as the house sparrow (Passer domesticus), Madagascar turtle-dove (Nesoenas picturatus), and common myna (Acridotheres tristis) have also been observed near the cave and can be in direct contact with bat guano. Further investigations involving sampling of individual bats and other host species in the vicinity of the cave, as well as sequencing of the AstV capsid gene, could provide information on the level of potential cross-species transmission in this ecosystem. 


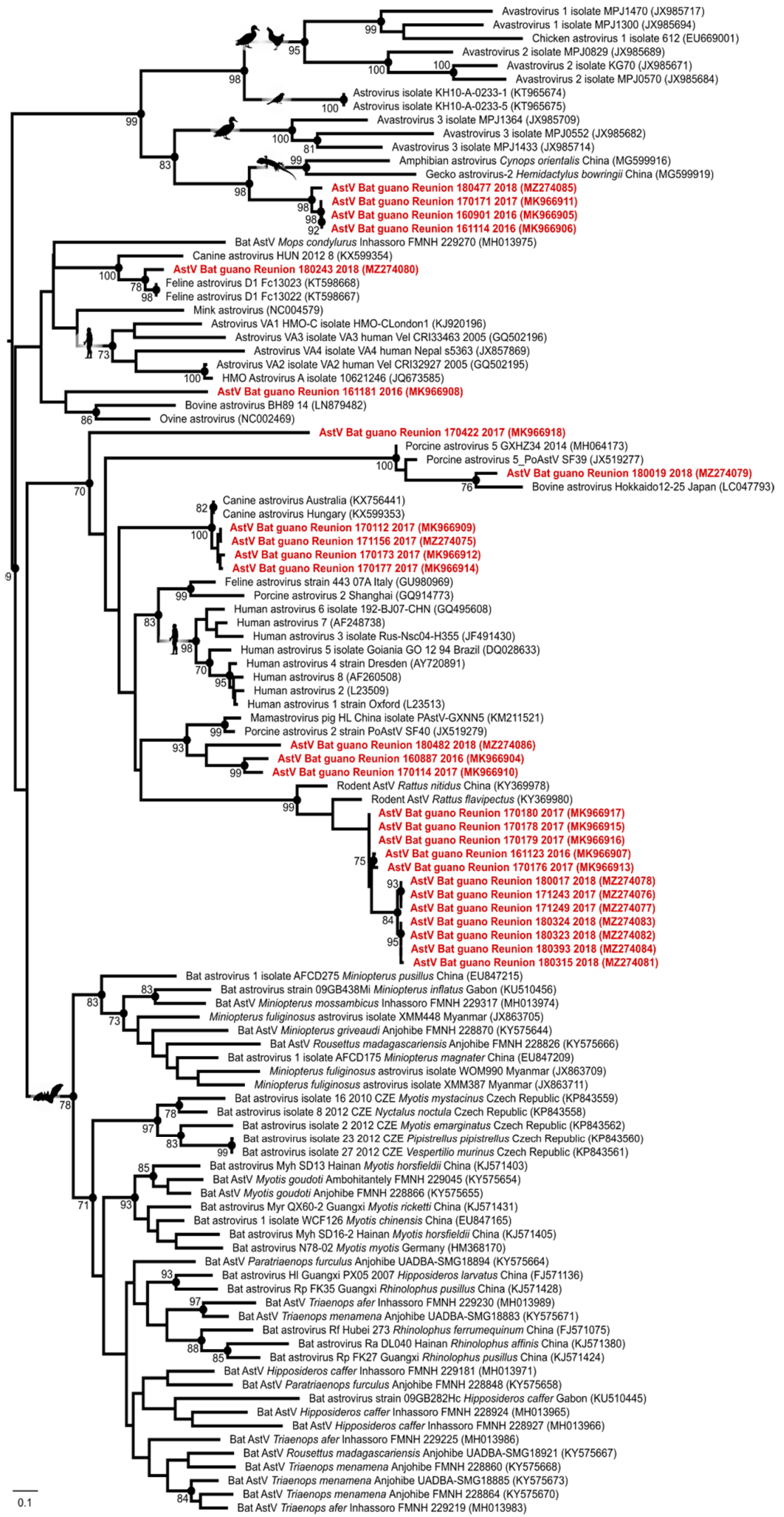

Figure 2. Maximum likelihood consensus tree derived from 111 Astrovirus (AstV) RNA-dependent RNA-polymerase partial nucleotide sequences (390 bp). Black dots indicate nodes with bootstrap values higher or equal than 70 . Red: sequences generated in this study. Scale bar: mean number of nucleotide substitutions per site. 
Supplementary Materials: The following are available online at https://www.mdpi.com/article/10 .3390/v13081524/s1, Figure S1: Cave entrance of the studied colony, Figure S2: Sampling transect at the cave entrance.

Funding: This study was funded by the VIROPTERE program (INTERREG V Océan Indien). Léa Joffrin was supported by a "Région Réunion, European Regional Development Funds (FEDER 20142020)" PhD fellowship, Axel Hoarau by a "Ministère de l'Enseignement supérieur, de la Recherche et de l'Innovation" PhD fellowship, and Camille Lebarbenchon by a "Chaire Mixte Institut National de la Santé et de la Recherche Médicale (INSERM)—Université de La Réunion".

Institutional Review Board Statement: Not applicable.

Informed Consent Statement: Not applicable.

Data Availability Statement: All data are available as part of this publication, in the Supplementary Materials and sequence accession numbers cited in the manuscript.

Acknowledgments: We thank Muriel Dietrich and Nicolas Diotel for their assistance in the field.

Conflicts of Interest: The authors have no conflict of interests.

\section{References}

1. De Benedictis, P.; Schultz-Cherry, S.; Burnham, A.; Cattoli, G. Astrovirus infections in humans and animals-molecular biology, genetic diversity, and interspecies transmissions. Infect. Genet. Evol. 2011, 11, 1529-1544. [CrossRef]

2. Bosch, A.; Guix, S.; Krishna, N.K.; Méndez, E.; Monroe, S.S.; Pantin-Jackwood, M.; Schultz-Cherry, S. Virus Taxonomy: Ninth Report of the International Committee on Taxonomy of Viruses; King, A.M.Q., Lefkowitz, E., Adams, M.J., Carstens, E., Eds.; Elsevier: San Diego, CA, USA, 2011.

3. Fischer, K.; dos Reis, V.P.; Balkema-buschmann, A. Bat Astroviruses: Towards understanding the transmission dynamics of a neglected virus family. Viruses 2017, 9, 34. [CrossRef]

4. Chu, D.K.W.; Leung, C.Y.H.; Perera, H.K.K.; Ng, E.M.; Gilbert, M.; Joyner, P.H.; Poon, L.L.M. A novel group of avian astroviruses in wild aquatic birds. J. Virol. 2012, 86, 13772-13778. [CrossRef]

5. Rivera, R.; Nollens, H.H.; Venn-Watson, S.; Gulland, F.M.D.; Wellehan, J.F.X. Characterization of phylogenetically diverse astroviruses of marine mammals. J. Gen. Virol. 2010, 91, 166-173. [CrossRef]

6. Karlsson, E.A.; Small, C.T.; Freiden, P.; Feeroz, M.M.; Matsen, F.A.; San, S.; Schultz-Cherry, S. Non-human primates harbor diverse mammalian and avian astroviruses including those associated with human infections. PLoS Pathog. 2015, 11, e1005225. [CrossRef]

7. Mendenhall, I.H.; Smith, G.J.D.; Dhanasekaran, V. Ecological drivers of virus evolution: Astrovirus as a case study. J. Virol. 2015, 89, 6978-6981. [CrossRef]

8. Bosch, A.; Pinto, R.M.; Guix, S. Human Astroviruses. Clin. Microbiol. Rev. 2014, 27, 1048-1074. [CrossRef]

9. Hoarau, F.; Le Minter, G.; Joffrin, L.; Schoeman, M.C.; Lagadec, E.; Ramasindrazana, B.; Lebarbenchon, C. Bat astrovirus in Mozambique. Virol. J. 2018, 15, 1-5. [CrossRef]

10. Rougeron, V.; Suquet, E.; Maganda, G.D.; Jiolle, D.; Mombo, I.M.; Bourgarel, M.; Leroy, E.M. Characterization and phylogenetic analysis of new bat astroviruses detected in Gabon, Central Africa. Acta Virol. 2016, 60, 386-392. [CrossRef]

11. Waruhiu, C.; Ommeh, S.; Obanda, V.; Agwanda, B.; Gakuya, F.; Ge, X.Y.; Shi, Z.L. Molecular detection of viruses in Kenyan bats and discovery of novel astroviruses, caliciviruses and rotaviruses. Virol. Sin. 2017, 32, 101-114. [CrossRef]

12. Yinda, C.K.; Ghogomu, S.M.; Conceição-Neto, N.; Beller, L.; Deboutte, W.; Vanhulle, E.; Matthijnssens, J. Cameroonian fruit bats harbor divergent viruses, including rotavirus $\mathrm{H}$, bastroviruses, and picobirnaviruses using an alternative genetic code. Virus Evol. 2018, 4, 1-15. [CrossRef]

13. Drexler, J.F.; Corman, V.M.; Wegner, T.; Tateno, A.F.; Zerbinati, R.M.; Gloza-Rausch, F.; Drosten, C. Amplification of emerging viruses in a bat colony. Emerg. Infect. Dis. 2011, 17, 449-456. [CrossRef]

14. Mendenhall, I.H.; Skiles, M.M.; Neves, E.S.; Borthwick, S.A.; Low, D.H.W.; Liang, B.; Smith, G.J.D. Influence of age and body condition on astrovirus infection of bats in Singapore: An evolutionary and epidemiological analysis. One Health 2017, 4, 27-33. [CrossRef]

15. Seltmann, A.; Corman, V.; Rasche, A.; Drosten, C.; Czirjak, G.; Bernard, H.; Voigt, C. Seasonal fluctuations of astrovirus, but not coronavirus shedding in bats inhabiting human-modified tropical forests. Ecohealth 2017, 14, 272-284. [CrossRef]

16. Goodman, S.M. Les Chauves-Souris de Madagascar; Association Vahatra: Antananarivo, Madagascar, 2011.

17. Goodman, S.M.; Schoeman, M.C.; Rakotoarivelo, A.; Willows-Munro, S. How many species of Hipposideros have occurred on Madagascar since the Late Pleistocene? Zool. J. Linn. Soc. 2016, 177, 428-449. [CrossRef]

18. Foley, N.M.; Goodman, S.M.; Whelan, C.V.; Puechmaille, S.J.; Teeling, E. Towards navigating the Minotaur's labyrinth: Cryptic diversity and taxonomic revision within the speciose genus Hipposideros (Hipposideridae). Acta Chiropterologica 2017, 19, 1-18. [CrossRef] 
19. Goodman, S.M.; Jansen van Vuuren, B.; Ratrimomanarivo, F.; Probst, J.; Bowie, R.; Group, E.G.; Re, L. Specific status of populations in the mascarene islands referred to Mormopterus acetabulosus (chiroptera: Molossidae), with description of a new species. J. Mammal. 2008, 89, 1316-1327. [CrossRef]

20. Dietrich, M.; Wilkinson, D.A.; Benlali, A.; Lagadec, E.; Ramasindrazana, B.; Dellagi, K.; Tortosa, P. Leptospira and paramyxovirus infection dynamics in a bat maternity enlightens pathogen maintenance in wildlife. Environ. Microbiol. 2015, 17, 4280-4289. [CrossRef]

21. Lebarbenchon, C.; Ramasindrazana, B.; Joffrin, L.; Bos, S.; Lagadec, E.; Le Minter, G.; Mavingui, P. Astroviruses in bats, Madagascar. Emerg. Microbes Infect. 2017, 6, e58. [CrossRef]

22. Chu, D.K.W.; Poon, L.L.M.; Guan, Y.; Peiris, J.S.M. Novel astroviruses in insectivorous bats. J. Virol. 2008, 82, 9107-9114. [CrossRef] [PubMed]

23. R Core Team. R: A language and environment for statistical computing. In R Foundation for Statistical Computing; R Foundation for Statistical Computing: Vienna, Austria, 2018.

24. Guindon, S.; Dufayard, J.-F.; Lefort, V.; Anisimova, M.; Hordijk, W.; Gascuel, O.; Gascuel, O. New algorithms and methods to estimate maximum-likelihood phylogenies: Assessing the performance of PhyML 3.0. Syst. Biol. 2010, 59, 307-321. [CrossRef]

25. Keane, T.M.; Creevey, C.J.; Pentony, M.M.; Naughton, T.J.; Mclnerney, J.O. Assessment of methods for amino acid matrix selection and their use on empirical data shows that ad hoc assumptions for choice of matrix are not justified. BMC Evol. Biol. 2006, 6, 29. [CrossRef]

26. Mildenstein, T.; de Jong, C. Natural history, ecological and socio-economic value of bats. In Investigating the Role of Bats in Emerging Zoonoses; Newman, S.H., Field, H., Epstein, J., de Jong, C., Eds.; FAO Animal; Food and Agriculture Organisation of the United Nations: Rome, Italy, 2011; pp. 15-28.

27. Joffrin, L.; Dietrich, M.; Mavingui, P.; Lebarbenchon, C. Bat pathogens hit the road: But which one? PLoS Pathog. 2018, 14, e1007134. [CrossRef]

28. Donato, C.; Vijaykrishna, D. The broad host range and genetic diversity of mammalian and avian astroviruses. Viruses 2017, 9, 102. [CrossRef]

29. Yi, S.; Niu, J.; Wang, H.; Dong, G.; Guo, Y.; Dong, H.; Hu, G. Molecular characterization of feline astrovirus in domestic cats from Northeast China. PLoS ONE 2018, 13, e0205441. [CrossRef] [PubMed] 